Kopmann J, Kock A, Killen C P (2017), “Chapter 7: Project Portfolio Management - the Linchpin for Strategy Formation”, In Sankaran S, Muller R, Drouin N (eds.), Handbook of Organizational Project Management, Cambridge University Press, Cambridge. pp 92-105.

\title{
Chapter 7: Project Portfolio Management
}

\section{- the Linchpin in Strategy Processes}

\author{
Julian Kopmann, Alexander Kock and Catherine P Killen
}

\begin{abstract}
This chapter explores the role of project portfolio management in the relationship between the formulation and implementation of strategy. Extant research on project portfolio management focuses primarily on the implementation aspects, particularly the functions that aim for strategic fit and the realization of intended strategies under relatively stable conditions. This chapter adapts a process model to highlight specific project portfolio management tasks in the interplay between strategy formulation and implementation. We show that project portfolio management is not only a means for strategy implementation, but can also play an active role in enabling organizations to adapt to changing conditions, thus providing the impetus for the creation of new strategic initiatives.
\end{abstract}

Keywords: project portfolio management, strategy formation, strategy implementation, emergent strategy, strategic control

\section{Introduction}

Project portfolio management (PPM) is a central component of organizational project management (OPM), especially through its role in both the formulation and the delivery of organizational strategy. Corporate activities are increasingly carried out in the form of 
projects, in a trend that has been called 'projectification' (Midler, 1995). In particular, for the implementation of complex innovations, it is not enough for organizations to focus on the successful management of individual innovation projects; they must also manage a large number of interdependent projects from a portfolio perspective. In today's dynamic environment, organizing by projects has become the rule rather than the exception, and organizations face challenges in managing these large project landscapes (programs and portfolios).

The management of project portfolios is closely linked to the implementation of strategies. As strategies are ultimately implemented by projects, PPM - as a link between corporate strategy and projects — plays a central role (Meskendahl, 2010). In most research and practice this role is considered from a top-down perspective: strategies are considered to be a given yardstick for the prioritization and selection of projects and the allocation of resources. From such perspectives, PPM acts as the recipient of strategic goals and requirements that need only to be operationalized.

However, the strategic management literature has long recognized the importance of emergent strategy; and that the realized strategy (the strategy that is actually implemented) often strays from the intended strategy (Mintzberg, 1978). Surprisingly, this is hardly considered in existing research models and standards for PPM (PMI, 2013). While there is some empirical evidence to suggest that hierarchical, formal, top-down approaches are not the actual practice of PPM (Christiansen \& Varnes, 2009; Jerbrant \& Gustavsson, 2013; Martinsuo, 2013), a much broader debate is needed to fully explore the role of PPM in the context of emergent strategies. The goal of this chapter is therefore to explore the role of PPM in the relationship between the formulation and implementation of strategy and consider both the top-down approach as well as the bottom-up strategy emergence. We first discuss emergence in the context of strategy implementation and the role of different phases in the 
PPM process that affect strategy implementation. After a discussion of the current empirical evidence on emergence in the context of portfolio management, we suggest ways in which PPM can act as a strategy 'linchpin'; an essential organizational process to connect and integrate both top-down and bottom-up approaches in strategy implementation.

\section{Strategy formation and emergence}

Organizational strategy aims to underpin success through the development and maintenance of competitive advantages. In pursuit of such advantages, strategic processes are used to determine objectives and goals, and to develop plans for their achievement. The strategy formation process is often represented in two stages in strategic management literature. The first stage, strategy formulation, receives the large majority of the attention and researchthis is the stage where organizations weigh up the options and challenges and set goals and objectives aimed to lead the organization to success. The second stage, strategy implementation, refers to the ways the strategy becomes a reality; without effective strategy implementation, the planned strategies will not be realized. Although the importance of strategy implementation is well recognized, it is often treated as an afterthought to strategy formulation (Noble, 1999).

The theme of emergence has made a strong impact on the field of strategic management ever since Mintzberg's seminal work on strategy formation (Mintzberg, 1978). More generally, emergence refers to the appearance of new, coherent and unexpected structures, patterns and characteristics at the macro level of complex systems that are caused by the interaction of components at the micro level (Goldstein, 1999). Emergent phenomena have features that are not observable in the individual parts of the system (Akgün, Keskin, \& Byrne, 2014; Beeson \& Davis, 2000; Goldstein, 1999). Therefore, they are neither predictable nor deducible. They are based on self-organized behaviors through which simple behavioral rules at the local level 
can lead to very complex behaviors at the global level (Goldstein, 1999). Emergence can occur in physical, biological, technical or social systems.

Organizations today face strategic challenges as environments are increasingly characterized by high levels of change; strategic evolution, often led by emergent elements, is required to effectively respond to this change. Emphasizing emergence in organizations in the context of strategy formation, Mintzberg and Waters (1985) address the discrepancy between strategic plans and intentions on the one hand (strategy formulation) and what organizations actually do on the other hand (strategy implementation). These two aspects of implemented strategy are referred to as the deliberate strategy (implemented as intended), and emergent strategy (realized despite planning or even in the absence of plans). In addition, some of the intended strategy may not be implemented-referred to as unrealized strategy. Figure 7.1. illustrates these relationships. While strategy formulation is a purely mental, planning activity, implementation reflects the process of realization. Emergence, by definition, only occurs in the context of implementation, since it is an unexpected outcome.

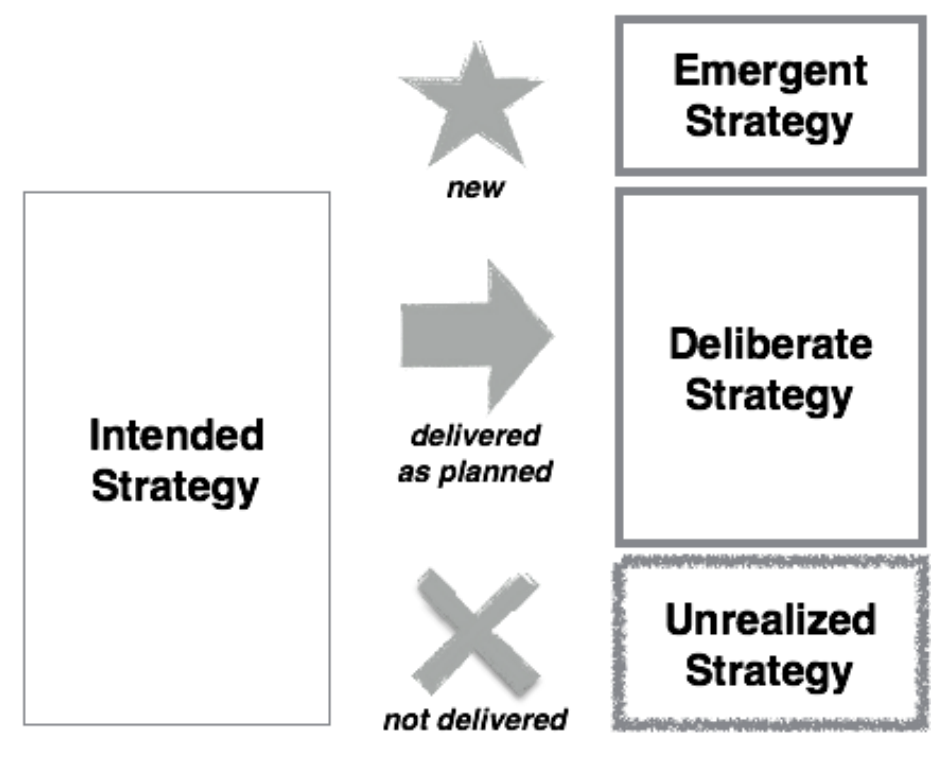

Figure 7.1. The relationship between intended and realized strategy (based on Mintzberg \& Waters, 1985) 
Although strategic plans are often made with an assumption that the strategy will be fully and deliberately implemented, this is very unlikely to occur in reality. A perfectly deliberate strategy implementation requires that strategic intentions are fully developed and communicated, all organizational actors are fully committed to implementing the strategy, and there is no interference from external forces. In today's increasingly turbulent environment, external change is especially likely to affect the implementation of strategic plans. Similarly, a purely emergent strategy is also highly unlikely to occur, as that would indicate that intention had no role to play at all. Instead, it is the combination of the two (deliberate and emergent strategy) that is observed in practice. Mintzberg and Waters (1985, p. 271) state it this way: strategy formation "walks on two feet, one deliberate, the other emergent". This suggests that management needs an ability to provide direction while simultaneously responding to change and emergence. Other researchers use different terms for similar concepts-for example, a commanding/directing mode of top-down strategy implementation combined with a generative/responding mode of bottom-up strategy implementation is proposed to lead to better outcomes than either mode on its own (Hart, 1992).

To explore the concept of emergence, we now turn our attention to strategy implementation in a project environment. In organizations, strategies are typically implemented by projects; as the project portfolio represents the sum of all projects, it therefore also represents the currently implemented strategy (Morgan, Levitt, \& Malek, 2008). Strategic implementation through portfolio mechanisms is characterized by high complexity and multiple inter-element interactions - conditions that suggest an environment ripe for the occurrence of emergence. Individual projects and actors represent the main elements or components of this system at the micro level (Goldstein (1999), and their interaction may result in emergence on a higher 
portfolio and strategy level. It should be noted that not every such interaction leads to emergence; the interactions must also have coherent structures. These structures, however, are only visible from a higher level; a portfolio perspective can reveal how such micro-level elements form higher-level structures from the bottom-up. Therefore, the concerted management of these elements is best done from the portfolio level through PPM mechanisms (see Figure 7.2.).

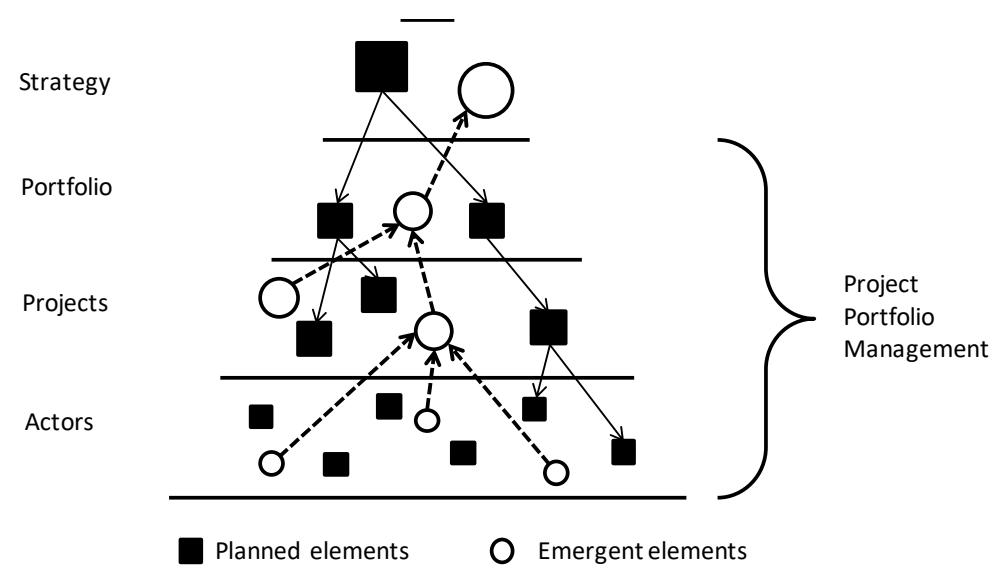

Figure 7.2: A project portfolio perspective of planned and emergent strategic elements

PPM is therefore often viewed as a bridge between strategy formulation and its implementation (Meskendahl, 2010). The challenge of PPM lies not only in the implementation of deliberate strategy but also in the adequate handling, and indeed enabling, of emergence. While planned strategies are cascaded down through the hierarchy for implementation, emergent strategy is realized by the bottom-up interplay of different portfolio elements (people and projects).

The project prioritization and selection phase of PPM receives strong attention for its impact on strategy (Archer \& Ghasemzadeh, 2004; Blichfeldt \& Eskerod, 2008; Dietrich \& Lehtonen, 2005; Englund \& Graham, 1999; Müller, Martinsuo, \& Blomquist, 2008). The cascade model of strategy implementation is often portrayed as the mechanism through which 
projects are selected to fit with strategy through a traditional top-down approach (see Figure 7.3.). This perspective focuses on the realization of deliberate strategies, ignoring the potential existence and impact from emergent strategies.

\section{Degree of Strategy Implementation}

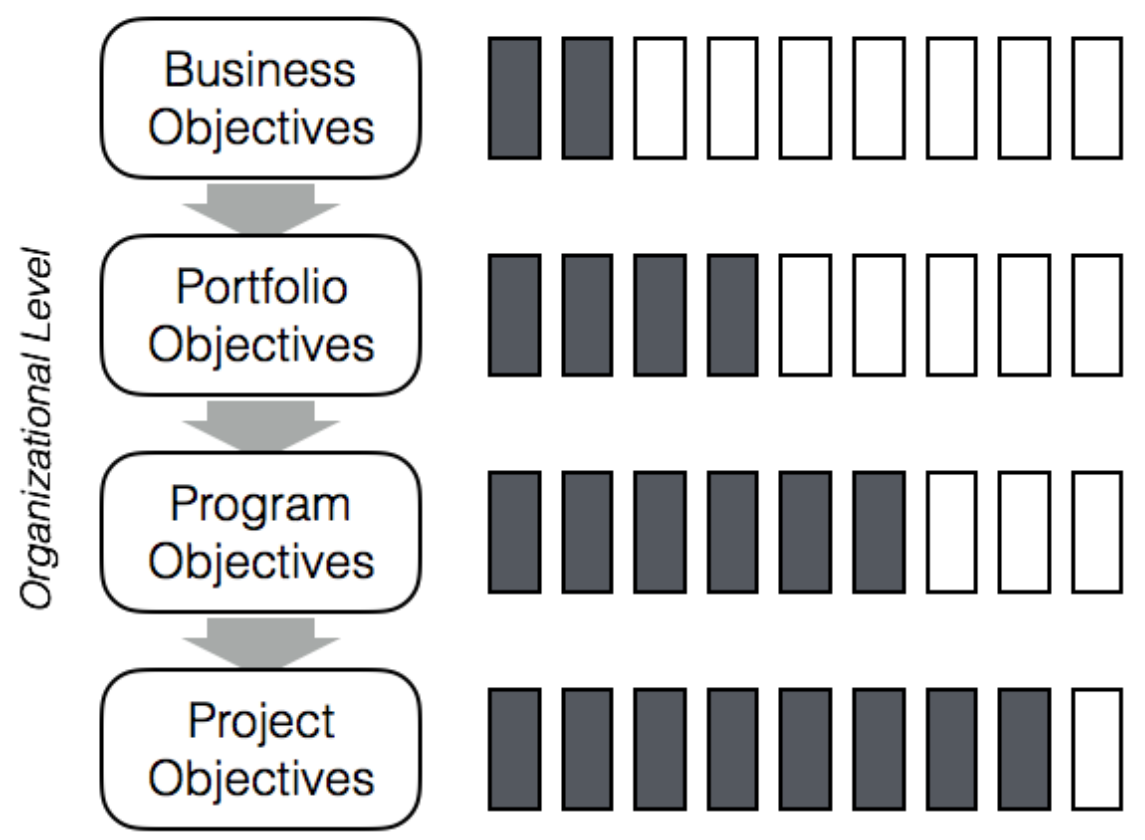

Figure 7.3: Cascade model (extended from Morris and Jamieson, 2005)

The top-down cascade model is reflected in much of the extant OPM research. Empirical studies confirm a positive relationship between strategically aligned project selection and portfolio success (Müller et al., 2008). Other studies have shown that a formalized portfolio management process, which is based on strategic planning, is also associated with success, as it provides transparency, facilitates coordination and enables strategy to guide project selection (Schultz, Salomo, de Brentani, \& Kleinschmidt, 2013; Teller, Unger, Kock, \& Gemünden, 2012). Finally, successful portfolios are also characterized by clear objectives for projects and formalized decision processes (Martinsuo \& Lehtonen, 2007). 
The dominant view on PPM as represented by these and other studies is driven from the top down and ignores that strategy can also be emergent (Mintzberg, 1978). In the next section we discuss the PPM process and how it works with strategy formulation and implementation in both a top-down and a bottom-up manner.

\section{Project Portfolio Management Process}

A project portfolio describes a set of projects that are executed by a particular organization and compete for its limited resources in terms of budget, personnel, and time (Archer \& Ghasemzadeh, 2004). It can be said that the project portfolio represents the organization's strategy (Benko \& McFarlan, 2003; Morgan et al., 2008) as it is a collection of the projects and programs that embody strategy realization. The project portfolio processes also guide the future implementation of strategy through projects (Cooper, Edgett, \& Kleinschmidt, 1999). Therefore, the dedicated management of a project portfolio is responsible for the prioritization of projects and the respective allocation of scarce resources in order to realize the most favorable selection of projects for an organization (Blichfeldt \& Eskerod, 2008). In addition, PPM refers to the continuous and overarching coordination and steering of the project portfolio. In that regard, the management of a project portfolio can provide benefits (e.g., exploitation of synergies between projects and management of portfolio risks) that would not occur in case of independently managed projects (Teller \& Kock, 2013).

Scholars often adapt a process model for describing portfolio-related management activities (e.g., Blichfeldt \& Eskerod, 2008; Thiry \& Deguire, 2007). Such process models typically highlight the role of project prioritization and selection and the ongoing coordination of the portfolio of projects. In this chapter, we follow the model by Jonas (2010) that comprises four phases (see also Beringer, Jonas, \& Kock, 2013; Jonas, Kock, \& Gemünden, 2013; Meskendahl, 2010): 1) Project portfolio structuring; 2) Resource allocation; 3) Project 
portfolio steering; and 4) Project portfolio exploitation. This varies from other models by including a fourth phase, which comprises the post-project activities and emphasizes the exploitation of project results (Jonas, 2010). One weakness of phase-based process models is that they tend to suggest a static view of the life cycle of projects; however, project portfolios are highly dynamic entities (Floricel \& Ibanescu, 2008; Petit, 2012). New project opportunities and proposals are constantly popping up while the scope and urgency of ongoing projects may change at any time. Changing strategic objectives and the impact of a volatile environment can alter the priority and purpose of projects while other projects may become obsolete. As a consequence, aspects of PPM referring to the inflow of projects, to the continuous management of the stock of projects, and to the outflow of projects, need to be performed simultaneously and constantly. In the following sections, we highlight the main activities, challenges, and contributions of the four phases of PPM on strategy implementation.

Portfolio structuring comprises activities that precede the execution of projects. The main challenge of this phase is to define a portfolio of project investments that in its entirety optimally reflects the strategic objectives while also considering the constraints of the funding organization.

This requires:

- management of the inflow of project ideas and proposals (Heising, 2012; Kock, Heising, \& Gemünden, 2015; Kock, Heising, \& Gemünden, 2016)

- prioritization and balancing between multiple potentially contradicting goals, aiming for strategic alignment, maximal revenues, and a balanced portfolio of risks (Cooper, Edgett, \& Kleinschmidt, 2001; Meskendahl, 2010)

- management of dependencies on the internal and external environment and between projects (Archer \& Ghasemzadeh, 1999; Killen, 2013; Killen \& Kjaer, 2012; Platje, 
Seidel, \& Wadman, 1994)

- integration of input from relevant stakeholders such as the project customers (Voss, 2012; Voss \& Kock, 2013)

As a result, a portfolio of preferred project investments is selected from a wide range of project ideas that have gone through a comprehensive evaluation and prioritization. In sum, this selected portfolio represents an interpretation of a top-level strategy that is used to derive project initiatives and to challenge and evaluate upcoming project ideas. Thus, from a strategic management perspective the selected portfolio represents the nexus between strategy formulation and implementation. On the one hand, it drives strategy formulation by interpreting the strategy, concretizing it to project evaluation criteria or by defining strategic bucket. On the other, the actual selection of projects represents the first step of the implementation of the intended strategy. However, it is not all top-down, and in this phase we also observe the influence of bottom-up elements (e.g., due to operational problems that require solutions or new project ideas that are not in line with the overall strategic direction).

Resource allocation refers to the distribution of the organization's resources across the projects in a way that reflects the organization's priorities. The main challenge of this phase stems from the tension between the line organization that provides the resources and the project organization that requires the resources (Arvidsson, 2009). The optimal utilization of resources requires the transparency of their availability and competences, a clear strategic focus, and a commitment to organizational goals that prevent opportunistic behavior (Elonen \& Artto, 2003; Engwall \& Jerbrant, 2003). Another challenge is indicated by issues at the individual level. Project members often lack the long-term perspectives and career systems that a single project environment cannot provide while their allocation to multiple projects often leads to an overload of project work (Huemann, 2010; Zika-Viktorsson, Sundström, \& 
Engwall, 2006). Organizations that successfully address these challenges provide the basis for the efficient implementation of the portfolio of project ideas.

The impact of the resource allocation phase on the strategy formation process is twofold. First, it provides the basis for the efficient implementation of the entire portfolio of project ideas according to the organization's priorities and thereby concretizes the intended strategy that is inherent to the project ideas in funded and staffed projects. It paves the way and defines the frame for strategy implementation. Second, in the resource allocation phase, the commitment of the (resource-owning) middle management (typically in the line organization) to the strategy is revealed. In some cases, the lack of resource commitments to support strategic decisions have been seen as a major source of emergent strategies (Burgelman, 1994).

Portfolio steering comprises all activities that are related to ongoing projects. Through continuous coordination and control activities, PPM provides mechanisms for response to changing organizational priorities, project plan deviations, and/or risks and opportunities (Korhonen, Laine, \& Martinsuo, 2014; Müller et al., 2008; Teller \& Kock, 2013). In doing so, this phase addresses challenges that stem from a dynamic external and internal environment and enables an organization to adapt to changing conditions. Scholars also emphasize the importance of the exploitation of synergies among projects regarding the availability of information, or the mutual utilization of tangible or intangible assets (Canonico \& Söderlung, 2010; Platje et al., 1994).

The strategic relevance of this phase is, again, twofold. First, portfolio steering can provide strategic control functions to ensure alignment with strategy and to manage uncertainty (Korhonen et al., 2014). Second, a portfolio perspective of current projects can create and reveal strategic opportunities that emerge within the strategy implementation (Kopmann, Kock, Killen, \& Gemünden, 2014). 
Portfolio exploitation activities refer to the project closure and the post-project phase. The scarce literature on PPM regarding this phase particularly highlights the relevance of organizational learning through 'lessons learned' and the evaluation of project results (Kopmann, Kock, Killen, \& Gemunden, 2015; Prencipe \& Tell, 2001; von Zedtwitz, 2002). This phase is also highly relevant, from a single-project perspective, on benefits realization (Winter \& Szczepanek, 2009). Scholars distinguish three stages in the process of value realization: output, outcome, and benefit (Turner \& Zolin, 2012; Winter \& Szczepanek, 2009; Zwikael \& Smyrk, 2012). Accordingly, the immediate results of a project (i.e., artifacts produced by the project) are defined as output. Projects are typically concluded when these outputs are delivered. However, the utilization and exploitation of these outputs is required to realize an outcome. Finally, benefits are described as the "flow of value that is triggered by the realization of a target outcome" (Zwikael \& Smyrk, 2012, p. 11). Following this rationale, the actual realization of a strategy takes place in the exploitation phase, after the delivery of outputs.

Thus, the main challenge in this phase is to bring together the puzzle pieces that are represented by the single projects (selected in the portfolio structuring phase), from the perspectives of both deliberate and emergent strategies, to fully understand and manage portfolio exploitation.

Deliberate strategies are based on one intended strategy concept, formulated in the beginning of the strategy formation process. As shown in Figure 2, the strategy cascades down into many micro-level elements. In the portfolio exploitation phase, these elements need to be brought together so that, from a 'big picture', portfolio-level perspective, the strategy implementation can best be recognized (and validated). However, emergent strategies also stem from multiple micro-level elements and realized strategy can only be fully recognized from an ex-post perspective, when patterns across these elements can be observed. The 
interplay between the top-down and bottom-up strategy processes contributes to a feedback loop where the formulated intended strategy evolves in response to emergence (Mintzberg \& Waters, 1985). It is at the portfolio perspective, and through PPM processes, that patterns of emergence come to light, and influence the ongoing (re)formulation of intended strategy.

Each of the four phases that have been discussed represents an essential and necessary part of PPM. Even though the phases overlap in practice, with activities often performed simultaneously, they are logically consecutive from a strategy perspective following the classical concept of deliberate strategy. This perspective also leads to a limited view of PPM as largely focused on the selection of the right projects.

This notion is also reflected in the widely acknowledged definition of project portfolio success, in which success is equated with the expected value of a portfolio of project investment options. As a consequence, scholars in PPM tend to focus on activities that are related to the operationalization and implementation of intended strategies, while its actual contribution to the bottom-up/emergent strategy formation is widely neglected. Thus, when revisiting the role of PPM in the strategy formation process, the understanding of portfolio success also needs to be challenged.

The strategic aspect of project portfolio success is traditionally seen in the implementation of the firm's strategy through portfolio structuring, resource allocation, and steering processes (Morris \& Jamieson, 2005). This view focuses on ensuring that project selection and resource allocation are aligned with the firm's strategic objectives and priorities in a top-down manner. Beyond that, successful PPM reconfigures the project portfolio through project reprioritization and termination to enforce strategic fit (Unger, Kock, Gemünden, \& Jonas, 2012). 
However, although strategic fit is one of the most prevalent success criteria for PPM, it only represents one side and ignores PPM's wider influence on strategy. In the end, it is the realized strategy that determines organizational success regardless of the degree to which it stems from intended top-down strategy or from emergent elements. To better understand the importance of emergence and the ways that PPM enables recognition of bottom-up emergence, we review the concept of emergence and emergent strategies from a PPM perspective in the following section.

\section{Evidence of Emergence in Project Portfolios}

Although the planning-based perspective dominates the literature on PPM, some qualitative studies give first indications of the importance of emergent phenomena:

- Burgelman (1983) identified autonomous strategic behavior as a source for strategic projects that are out of the organization's current strategic scope when initiated. Further, he proposes that strategy may follow autonomous strategic behavior when the middle managers make sense out of these initiatives and manipulate the strategic context accordingly. More explicitly, Mirabeau and Maguire (2014) explored several autonomous strategic projects that have led to emergent strategies and identified three aspects that foster the transition from autonomous strategic projects to emergent strategies: 1) Mobilizing wider support for impetus; 2) manipulating strategic context for consonance; and 3) altering structural context for embeddedness.

- Loch (2000) and Blichfeldt and Eskerod (2008) found that formal PPM is often only applied to specific projects, while many projects are executed outside formal decisionmaking processes. These unrecognized projects consume important resources and have a large impact on other projects. This suggests that emergent projects can present unresolved challenges to established management systems. 
- The investigations of Petit and Hobbs (2010) and Petit (2012) show that project portfolios are - due to high project interdependence — greatly affected by variations in project objectives, customer requirements and target customers during the course of individual projects. Similarly, managers are often unaware that risks of individual projects may aggregate at the portfolio level or that risks of individual projects may represent opportunities for other projects (Olsson, 2008; Teller, 2013). Many changes and unexpected events lead to unavoidable unpredictability, which is generally not well catered for in current portfolio management approaches.

- In a case study of a pharmaceutical company, Aaltonen (2010) identified evolutionary processes of variation, selection, and retention in project portfolios. These evolutionary processes can lead to path dependencies in portfolio decisions, resulting in co-selection where project selection according to certain criteria also results in unwanted aspects at the same time. Such evolutionary and unplanned developments (i.e., emergent strategy) are therefore shown to have strong implications for the entire portfolio.

- Bootlegging describes secretly organized innovation projects that ignore management directives. Hence, they are not under the control of portfolio management and do not follow the top-down defined selection process. Augsdorfer (2005) defines bootlegging as an activity that usually emerges bottom-up and might be beneficial for the firm. Augsdorfer's empirical study revealed that bootlegging takes place in $R \& D$ departments across multiple industries and primarily involves incremental innovations, which are eventually aligned with the corporate strategy and support the organization's goals. Hence, he argues that bootlegging is not only valuable commercially, but also in terms of strategic success.

- Midler's study of the development of the Renault Logan (2013) reveals the high 
relevance of emergent strategies for firm success in a multi-project environment. The case describes how an extremely successful strategy can develop evolutionarily through complex learning relationships among a series of interdependent projects. This strategy formation called "Lineage Management" describes a dialectic interplay between strategy formulation and implementation through a sequence of projects (Midler \& Silberzahn, 2008).

Other case studies also remind us that idealized project portfolio processes may not be in accordance with actual practice. Christiansen and Varnes (2009) observe that portfolio decisions are not necessarily made according to established rules and criteria, but instead rely strongly on negotiating, bargaining and intuition. Similarly, Jerbrant and Gustavsson (2013) demonstrate that the behavior of managers in PPM is often characterized by improvisation and does not necessarily reflect rational decision making. Kester, Griffin, Hultink, and Lauche (2011) identify that strong power-based and opinion-based decision-making processes are used in portfolio management, instead of the expected (and usually stipulated) evidence-based decision-making processes. Mosavi (2014) shows that portfolio management steering committees not only include a decision-making function as part of the established PPM approaches, but that they also include a communication and negotiation function that is not often formally recognized. A case study in the public sector (Young, Young, Jordan, \& O'Connor, 2012) shows that despite adoption of 'best practice' PPM approaches, the majority of projects contributed little to achieving strategic objectives, casting doubt on the suitability of current PPM approaches.

\section{Discussion and Suggestions for Managing Emergence through PPM}

We have shown how PPM is influenced by, and influences, both deliberate and emergent strategies. We have analyzed this relationship from a process perspective and have 
summarized empirical findings. Drawing upon our analysis of the findings, we now turn to the future to discuss how organizations might deal with emergent strategy implementation.

We offer three suggestions on how PPM can be adapted to recognize, allow and foster emergence. We propose that managers: 1) recognize the value of emergence and consider adopting mechanisms for 'planned emergence' via strategic control; 2) manage the 'grassroots' of strategy and foster bottom-up initiatives to allow for emergent elements; and 3) consider the wider role of PPM in two-way strategy processes, and the need to adapt PPM success measures accordingly. We then explore each of these suggestions on how organizations can best build on and manage emergence through PPM.

\section{Implementation of mechanisms for 'planned emergence' via strategic control}

In recognition of the importance of emergent strategy for organizational response to change, we turn to mechanisms within PPM that can help to manage emergence. The concept of 'managing emergence' may seem counterintuitive, as one of the defining features of emergence is that it is not planned. However, as highlighted by Mintzberg and Waters (1985, p. 271), "[i]t is important to remember that emergent strategy means, not chaos, but, in essence, unintended order". This suggests that emergence itself can be guided or steered, in a process sometimes called 'planned emergence' (Grant, 2003; Levina \& Su, 2008). A study of portfolio-level managerial controls reveals how such controls aid in the management of uncertainty and suggests that they can improve organizational ability to meet strategic objectives (Korhonen et al., 2014). We propose that strategic control mechanisms implemented at the portfolio level can play a role in managing emergence.

Strategic controls can take the form of diagnostic controls or interactive controls (Simons, 2013). While diagnostic controls have a role in motivating and rewarding strategic achievements, it is the interactive controls that are most relevant to managing emergence. 
Interactive controls provide a framework that allows for incremental and emergent strategy formation, facilitates learning, and addresses uncertainties that could affect the basis of competitive advantage (van Veen-Dirks \& Wijn, 2002). Such interactive controls can provide a "means for surfacing and acting upon emerging strategies" (Osborn, 1998, p. 488).

Schreyögg and Steinmann (1987) propose three steps for strategic control: Premise control refers to the ongoing verification of assumptions; Implementation control monitors the actuality of strategy via currently implemented and pursued strategic directions; and Strategic surveillance scans the environment to 'sense' elements (Schreyögg \& Steinmann, 1987, p. 97; Teece, 2009). In contrast to approaches that see strategy formulation, implementation, and evaluation as distinct sequential activities, Schreyögg and Steinmann show how mechanisms can simultaneously provide strategic control while also acting as a countervailing force to strategic planning (Band \& Scanlan, 1995; Goold \& Quinn, 1990; Preble, 1992; Schreyögg \& Steinmann, 1987). They promote a feed-forward concept where the ongoing monitoring of environmental change is used to anticipate the appearance of emergence (Schreyögg \& Steinmann, 1987), and to anticipate their effect on the intended strategy (Preble, 1992).

Management may find benefits and support for emergence from implementing strategic controls at the PPM level to review strategy while also supporting and promoting reformulation of strategy. The goal is to provide a mechanism for monitoring change to enable the identification of situations that may call for emergent strategies, help steer the emergence, and finally, from a portfolio perspective, to recognise patterns of emergence as they occur. 


\section{Managing emergence from bottom-up initiatives}

Emergence stems from the unplanned behavior of actors on an operational level. Coordinating emergence can take the form of an active role in attempting to channel emergence, or a slightly less proactive approach that accepts emergent elements while providing leeway and empowerment to foster emergent strategies. Examples of initiatives that seek to gain benefits from bottom-up emergence demonstrate a combination of acceptance and fostering of emergence along with approaches to channel or guide the emergence to achieve success:

- Decentralized project selection accepts emergence by instituting, for example, idea markets for project prioritization that attempts to channel this emergence by adopting a stock exchange logic (Soukhoroukova, Spann, \& Skiera, 2012), where project ideas are treated like virtual stocks employees can invest in. In the end, the market value of the virtual stock creates a form of 'channeling' to determine the priority of a project idea. Microsoft is using such techniques (Dahan, Soukhoroukova, \& Spann, 2010).

- Decentralized resource management that allows employees to self-allocate to projects also provides a way to accept and channel emergence. In this way, the most attractive project will attract the best resource pool and will have a better chance of successthe emergence is accepted by the creation of such structures, and the channeling is based on the employee's perspectives, which can evolve to represent organizational goals.

- In order to simultaneously allow for emerging elements while also channeling and exercising control, a combination of open and closed action strategies may be useful (Gebert, Boerner, \& Kearney, 2010). Open action strategies promote knowledge and idea generation (increased variability), whereas closed action strategies enhance knowledge integration (increasing alignment). For example, in a PPM context, Kock 
et al. (2015) showed that organizations that foster a climate of creative encouragement (open action strategy) and simultaneously formulate a clear ideation strategy and install clearly specified evaluation processes (closed action strategies) perform better than organizations that only follow either an open or a closed action strategy.

- Emergence may be fostered and accepted by strengthening the autonomy and power of middle managers and project managers by giving them more voice (Hirschman, 1970). Voice behavior is defined as "discretionary communication of ideas, suggestions, concerns, or opinions about work-related issues with the intent to improve organizational or unit functioning” (Morrison, 2011, p. 375). Promoting voice behaviour of project managers could enhance organizational effectiveness by fostering constructive emergence of issues regarding opportunities and threats alike. Ekrot, Rank, and Gemünden (2016) show that project manager's voice behavior is positively affected by idea encouragement, career perspectives, qualification opportunities and peer collaboration, but only if project managers have a high level of self-perceived competence and importance for the organization (i.e., organizationbased self-esteem).

- Institutionalized bootlegging promotes emergence by allowing employees to freely choose how to spend $10-20 \%$ of their work time (e.g., Google or $3 \mathrm{M}$ ) for innovative projects. Promising projects can then be channeled through additional encouragement or funding.

Management of OPM may be enhanced through the use of these types of combinations of approaches to accept, empower, and channel emergence. 


\section{Adjust project portfolio success metrics}

Commonly used measures of PPM success largely stem from the traditional top-down view of strategy implementation. In recognition of the role of emergence in strategy processes, we propose that there is a need to review and adjust PPM success measures to ensure they reflect the wider role of PPM in the strategy process.

According to the traditional definition of Cooper et al. (2001) that is still widely used (e.g., Kester, Hultink, \& Griffin, 2014), project portfolio success is based on three elements: maximizing the project portfolio's value; linking the portfolio to the firm's strategy; and balancing the portfolio. Based on this definition, Kester et al. (2014) empirically investigated the impact of portfolio success on market performance. The only element of portfolio success that was found to contribute to market performance in terms of profit and market effectiveness was maximal value, while strategic alignment contributed only to customer satisfaction, and portfolio balance had no direct effect on market performance at all (Kester et al., 2014). These results suggest that Cooper et al.'s definition of project portfolio success may not provide a sufficient perspective to determine how strategy realization translates to the bottom line.

However, in the field of PPM research, several additional elements of portfolio success have been developed. For example, Jonas et al. (2013) augment traditional project success measures (time, cost, scope) with measures of customer satisfaction and the level of exploitation of synergies between projects. Heising (2012) and Voss (2012) applied a comprehensive definition of portfolio success by including a measure of future preparedness (building on the work of Shenhar, Dvir, Levy, \& Maltz, 2001), to evaluate the long-term benefits and opportunities offered by projects.

These evolutions in the ways that PPM success can be conceptualized have widened the view of the role of PPM; however, there remains room for improvement. The examples of 
emergence in OPM show that emergence is not merely a deviation from the plan (which is generally considered as negative), but that, if properly managed, emergence can have a positive impact on a firm's success (Midler, 2013). We propose two approaches for considering ways to adjust PPM success measures to reflect the fact that strategies are both deliberate and emergent. One approach is to measure the actual quality and success of the realized strategy, recognizing that success may take many forms and that the achievement of success is not dependent on whether the strategy is emergent or deliberate. The second approach is to separately evaluate the degree of successful implementation of intended strategies (through measuring strategic fit), and the degree of success in managing emergent strategies (i.e. recognizing emergent patterns and fostering their grassroots). The two approaches can work together and complement each other. While the first approach aims to provide a direct measure of strategic success, it depends on the reliable measurement of the actual quality and success of the strategy. The second approach offers a more detailed understanding of the nature of the strategy implementation and the degree to which the realized strategy reflects emergent and deliberate processes, but does not attempt to measure the actual quality and success of the strategy. An empirical analysis of the two approaches may also reveal under which circumstances a deliberate or an emergent strategy leads to more success.

This is an area of evolution and ongoing improvement; the development of adjusted PPM success measures will assist managers and academics to continue to learn more about the management of emergent strategy processes.

\section{Conclusions and Future Research}

In this chapter, we have shown that emergence is unavoidable in strategy implementation and thus should be considered in OPM. The question is not whether we need to manage emergence, but rather how to do it: fight it or embrace it. Modern organizations have 
established less hierarchical structures, more participative decision processes, and a culture of open discussions across all management levels. Why have they done so if not for the sake of bottom-up initiatives? The success of these organizations indicates that they were right to do so. However, the main challenge is to find the right balance between a strict and potentially more efficient top-down approach for strategy implementation and a more open and emergent approach where constant change could undermine the decision process. One avenue for future research could be to address this challenge and provide further guidance on the right balance through in-depth studies in a variety of environments. Such research could investigate whether and how PPM and portfolio-level mechanisms foster emergence, and whether particular contexts influence the effect.

By proposing PPM as the linchpin between top-down and bottom-up strategy processes, we demonstrate that this challenge can be addressed by a dedicated organizational function. Further, we have highlighted measures that complement the traditional approaches to managing project portfolios that focus on the implementation of intended strategies. Finally, we have called for a rethinking of project portfolio success measures-advocating that current approaches are extended to incorporate both the deliberate and emergent elements of successful strategies.

The importance of emergence is beginning to be recognized in OPM research. While the relevance of emergent strategies is widely acknowledged, there is a need for further research to provide clear managerial recommendations. By highlighting PPM's central role in managing emergence, we promote a discussion that will pave the way for further research as well as practitioner-relevant insights. Improving the ways that PPM can better support, and perhaps even guide, emergence is especially important due to the role of emergence in organizational responsiveness to meet changing conditions. 


\section{References}

Aaltonen, P. (2010). Co-selection in R\&D project portfolio management. Espoo: Helsinki University of Technology.

Akgün, A. E., Keskin, H., \& Byrne, J. C. (2014). Complex adaptive systems theory and firm product innovativeness. Journal of Engineering and Technology Management, 31, $21-42$.

Archer, N. P., \& Ghasemzadeh, F. (1999). An integrated framework for project portfolio selection. International Journal of Project Management, 17(4), 207-216.

Archer, N. P., \& Ghasemzadeh, F. (2004). Project portfolio selection and management. In P. W. G. Morris \& J. K. Pinto (Eds.), The Wiley guide to managing projects (pp. 237255). New York.

Arvidsson, N. (2009). Exploring tensions in projectified matrix organisations. Scandinavian Journal of Management, 25(1), 97-107.

Augsdorfer, P. (2005). Bootlegging and path dependency. Research Policy, 34(1), 1-11.

Band, D. C., \& Scanlan, G. (1995). Strategic control through core competencies. Long Range Planning, 28(2), 102-114.

Beeson, I., \& Davis, C. (2000). Emergence and accomplishment in organizational change. Journal of Organizational Change Management, 13(2), 178-189.

Benko, C., \& McFarlan, F. W. (2003). Connecting the dots: Aligning projects with objectives in unpredictable times: Harvard Business Press.

Beringer, C., Jonas, D., \& Kock, A. (2013). Behavior of internal stakeholders in project portfolio management and its impact on success. International Journal of Project Management, 31(6), 830-846. 
Blichfeldt, B. S., \& Eskerod, P. (2008). Project portfolio management-There's more to it than what management enacts. International Journal of Project Management, 26(4), $357-365$.

Burgelman, R. A. (1983). A model of the interaction of strategic behavior, corporate context, and the concept of strategy. Academy of Management Review, 8(1), 61-70.

Burgelman, R. A. (1994). Fading memories: A process theory of strategic business exit in dynamic environments. Administrative Science Quarterly, 39(1), 24-56.

Canonico, P., \& Söderlung, J. (2010). Getting control of multi-project organizations: combining contingent control mechanisms. International Journal of Project Management, 28(8), 796-806.

Christiansen, J. K., \& Varnes, C. J. (2009). Formal rules in product development: Sensemaking of structured approaches. Journal of Product Innovation Management, 26(5), 502-519.

Cooper, R. G., Edgett, S. J., \& Kleinschmidt, E. J. (1999). New product portfolio management: Practices and performance. Journal of Product Innovation Management, 16(4), 333-351.

Cooper, R. G., Edgett, S. J., \& Kleinschmidt, E. J. (2001). Portfolio management for new products (2nd ed.). Cambridge, MA: Perseus Pub.

Dahan, E., Soukhoroukova, A., \& Spann, M. (2010). New product development 2.0: Preference markets-How scalable securities markets identify winning product concepts and attributes. Journal of Product Innovation Management, 27(7), 937-954.

Dietrich, P., \& Lehtonen, P. (2005). Successful management of strategic intentions through multiple projects-Reflections from empirical study. International Journal of Project Management, 23(5), 386-391. 
Ekrot, B., Rank, J., \& Gemünden, H. G. (2016). Antecedents of project managers' voice behavior: The moderating effect of organization-based self-esteem and affective organizational commitment. International Journal of Project Management, 34(6), $1028-1042$.

Elonen, S., \& Artto, K. A. (2003). Problems in managing internal development projects in multi-project environments. International Journal of Project Management, 21(6), $395-402$.

Englund, R. L., \& Graham, R. J. (1999). From experience: Linking projects to strategy. Journal of Product Innovation Management, 16(1), 52-64.

Engwall, M., \& Jerbrant, A. (2003). The resource allocation syndrome: The prime challenge of multi-project management? International Journal of Project Management, 21(6), 403-409.

Floricel, S., \& Ibanescu, M. (2008). Using R\&D portfolio management to deal with dynamic risk. $R \& D$ Management, 38(5), 452-467.

Gebert, D., Boerner, S., \& Kearney, E. (2010). Fostering team innovation: Why is it important to combine opposing action strategies? Organization Science, 21(3), 593608.

Goldstein, J. (1999). Emergence as a construct: History and issues. Emergence, 1(1), 49-72.

Goold, M., \& Quinn, J. J. (1990). The paradox of strategic controls. Strategic Management Journal, 11(1), 43-57.

Grant, R. M. (2003). Strategic planning in a turbulent environment: Evidence from the oil majors. Strategic Management Journal, 24(6), 491-571.

Hart, S. L. (1992). An integrative framework for strategy-making processes. The Academy of Management Review, 17(2), 327-351. 
Heising, W. (2012). The integration of ideation and project portfolio management-A key factor for sustainable success. International Journal of Project Management, 30(5), $582-595$.

Hirschman, A. O. (1970). Exit, voice, and loyalty: Responses to decline in firms, organizations, and states. Cambridge, MA.

Huemann, M. (2010). Considering human resource management when developing a projectoriented company: Case study of a telecommunication company. International Journal of Project Management, 28(4), 361-369.

Jerbrant, A., \& Gustavsson, T. K. (2013). Managing project portfolios: Balancing flexibility and structure by improvising. International Journal of Managing Projects in Business, 6(1), 152-172.

Jonas, D. (2010). Empowering project portfolio managers: How management involvement impacts project portfolio management performance. International Journal of Project Management, 28(8), 818-831.

Jonas, D., Kock, A., \& Gemünden, H. G. (2013). Predicting project portfolio success by measuring management quality-A longitudinal study. IEEE Transactions on Engineering Management, 60(2), 215-226.

Kester, L., Griffin, A., Hultink, E. J., \& Lauche, K. (2011). Exploring portfolio decisionmaking processes. Journal of Product Innovation Management, 28(5), 641-661.

Kester, L., Hultink, E. J., \& Griffin, A. (2014). An empirical investigation of the antecedents and outcomes of NPD portfolio success. Journal of Product Innovation Management, 31(6), 1199-1213.

Killen, C. P. (2013). Evaluation of project interdependency visualizations through decision scenario experimentation. International Journal of Project Management, 31(6), 804816. 
Killen, C. P., \& Kjaer, C. (2012). Understanding project interdependencies: The role of visual representation, culture and process. International Journal of Project Management, $30(5), 554-566$.

Kock, A., Heising, W., \& Gemünden, H. G. (2015). How ideation portfolio management influences front-end success. Journal of Product Innovation Management, 32(4), $539-555$.

Kock, A., Heising, W., \& Gemünden, H. G. (2016). A contingency approach on the impact of front-end success on project portfolio success. Project Management Journal, 47(2), $115-129$.

Kopmann, J., Kock, A., Killen, C. P., \& Gemunden, H. G. (2015). Business case control in project portfolios-An empirical investigation of performance consequences and moderating effects. IEEE Transactions on Engineering Management, 62(4), 529-543.

Kopmann, J., Kock, A., Killen, C. P., \& Gemünden, H. G. (2014). The role of innovation portfolio management in the nexus between deliberate and emergent innovation strategies. Paper presented at the International Product Development Management Conference, Limerick.

Korhonen, T., Laine, T., \& Martinsuo, M. (2014). Management control of project portfolio uncertainty: A managerial role perspective. Project Management Journal, 45(1), 2137.

Levina, N., \& Su, N. (2008). Global multisourcing strategy: The emergence of a supplier portfolio in services offshoring. Decision Sciences, 39(3), 541-570.

Loch, C. (2000). Tailoring product development to strategy: Case of a European technology manufacturer. European Management Journal, 18(3), 246-258.

Martinsuo, M. (2013). Project portfolio management in practice and in context. International Journal of Project Management, 31(6), 794-803. 
Martinsuo, M., \& Lehtonen, P. (2007). Role of single-project management in achieving portfolio management efficiency. International Journal of Project Management, 25(1), 56-65.

Meskendahl, S. (2010). The influence of business strategy on project portfolio management and its success-A conceptual framework. International Journal of Project Management, 28(8), 807-817.

Midler, C. (1995). "Projectification" of the firm: The Renault case. Scandinavian Journal of Management, 11(4), 363-375.

Midler, C. (2013). Implementing a low-end disruption strategy through multiproject lineage management: The Logan case. Project Management Journal, 44(5), 24-35.

Midler, C., \& Silberzahn, P. (2008). Managing robust development process for high-tech startups through multi-project learning: The case of two European start-ups. International Journal of Project Management, 26(5), 479-486.

Mintzberg, H. (1978). Patterns in strategy formation. Management Science, 24(9), 934-948.

Mintzberg, H., \& Waters, J. A. (1985). Of strategies, deliberate and emergent. Strategic Management Journal, 6(3), 257-272.

Mirabeau, L., \& Maguire, S. (2014). From autonomous strategic behavior to emergent strategy. Strategic Management Journal, 35(8), 1202-1229.

Morgan, M., Levitt, R. E., \& Malek, W. A. (2008). Executing your strategy: How to break it down and get It down: Harvard Business School Publishing India Pvt. Limited.

Morris, P. W. G., \& Jamieson, A. (2005). Moving from corporate strategy to project strategy. Project Management Journal, 36(4), 5-18.

Morrison, E. W. (2011). Employee voice behavior: Integration and directions for future research. The Academy of Management Annals, 5(1), 373-412. 
Mosavi, A. (2014). Exploring the roles of portfolio steering committees in project portfolio governance. International Journal of Project Management, 32(3), 388-399.

Müller, R., Martinsuo, M., \& Blomquist, T. (2008). Project portfolio control and portfolio management performance in different contexts. Project Management Journal, 39(3), $28-42$

Noble, C. H. (1999). The eclectic roots of strategy implementation research. Journal of Business Research, 45(2), 119-134.

Olsson, R. (2008). Risk management in a multi-project environment: An approach to manage portfolio risks. International Journal of Quality \& Reliability Management, 25(1), $60-71$.

Osborn, C. S. (1998). Systems for sustainable organizations: Emergent strategies, interactive controls and semi-formal information. Journal of Management Studies, 35(4), 481509.

Petit, Y. (2012). Project portfolios in dynamic environments: Organizing for uncertainty. International Journal of Project Management, 30(5), 539-553.

Petit, Y., \& Hobbs, B. (2010). Project portfolios in dynamic environments: Sources of uncertainty and sensing mechanisms. Project Management Journal, 41(4), 46-58.

Platje, A., Seidel, H., \& Wadman, S. (1994). Project and portfolio planning cycle-Projectbased management for the multiproject challenge. International Journal of Project Management, 12(2), 100-106.

PMI. (2013). The standard for portfolio management-Third edition. Newtown Square (PA): Project Management Institute.

Preble, J. F. (1992). Towards a comprehensive system of strategic control. Journal of Management Studies, 29(4), 391-408. 
Prencipe, A., \& Tell, F. (2001). Inter-project learning: processes and outcomes of knowledge codification in project-based firms. Research Policy, 30(9), 1373-1394.

Schreyögg, G., \& Steinmann, H. (1987). Strategic control: A new perspective. Academy of Management Review, 91-103.

Schultz, C., Salomo, S., de Brentani, U., \& Kleinschmidt, E. J. (2013). How formal control influences decision-making clarity and innovation performance. Journal of Product Innovation Management, 30(3), 430-447.

Shenhar, A. J., Dvir, D., Levy, O., \& Maltz, A. C. (2001). Project success: A multidimensional strategic concept. Long Range Planning, 34(6), 699-725.

Simons, R. (2013). Levers of control: How managers use innovative control systems to drive strategic renewal: Harvard Business Review Press.

Soukhoroukova, A., Spann, M., \& Skiera, B. (2012). Sourcing, filtering, and evaluating new product ideas: An empirical exploration of the performance of idea markets. Journal of Product Innovation Management, 29(1), 100-112.

Teece, D. J. (2009). Dynamic capabilities and strategic management. Oxford: Oxford University Press.

Teller, J. (2013). Portfolio risk management and its contribution to project portfolio success: An investigation of organization, process, and culture. Project Management Journal, 44(2), 36-51.

Teller, J., \& Kock, A. (2013). An empirical investigation on how portfolio risk management influences project portfolio success. International Journal of Project Management, $31(6), 817-829$.

Teller, J., Unger, B. N., Kock, A., \& Gemünden, H. G. (2012). Formalization of project portfolio management: The moderating role of project portfolio complexity. International Journal of Project Management, 30(5), 596-607. 
Thiry, M., \& Deguire, M. (2007). Recent developments in project-based organisations. International Journal of Project Management, 25(7), 649-658.

Turner, R., \& Zolin, R. (2012). Forecasting success on large projects: Developing reliable scales to predict multiple perspectives by multiple stakeholders over multiple time frames. Project Management Journal, 43(5), 87-99.

van Veen-Dirks, P., \& Wijn, M. (2002). Strategic control: Meshing critical success factors with the balanced scorecard. Long Range Planning, 35(4), 407-427.

von Zedtwitz, M. (2002). Organizational learning through post-project reviews in R\&D. $R \& D$ Management, 32(3), 255-268.

Voss, M. (2012). Impact of customer integration on project portfolio management and its success-Developing a conceptual framework. International Journal of Project Management, 30(5), 567-581.

Voss, M., \& Kock, A. (2013). Impact of relationship value on project portfolio successInvestigating the moderating effects of portfolio characteristics and external turbulence. International Journal of Project Management, 31(6), 847-861.

Winter, M. C., \& Szczepanek, T. (2009). Images of projects. Burlington, VT: Gower.

Young, R., Young, M., Jordan, E., \& O'Connor, P. (2012). Is strategy being implemented through projects? Contrary evidence from a leader in new public management. International Journal of Project Management, 30(8), 887-900.

Zika-Viktorsson, A., Sundström, P., \& Engwall, M. (2006). Project overload: An exploratory study of work and management in multi-project settings. International Journal of Project Management, 24(5), 385-395.

Zwikael, O., \& Smyrk, J. (2012). A general framework for gauging the performance of initiatives to enhance organizational value. British Journal of Management, 23, S6S22. 
